\title{
The Role of Triglycerides in Atherosclerosis
}

\author{
Beatriz G. Talayero, $\mathbf{M D}^{1}$ and Frank M. Sacks, $\mathbf{M D}^{2}$ \\ ${ }_{1,2}$ Department of Nutrition, Harvard School of Public Health, Boston, MA \\ 2Department of Medicine, Harvard Medical School; and Brigham \& Women's Hospital, Boston, \\ MA
}

\begin{abstract}
Hypertriglyceridemia is a prevalent risk factor for cardiovascular disease (CVD) and increasingly important in the setting of current obesity and insulin resistance epidemics. High triglyceride (TG) levels are markers for several types of atherogenic lipoproteins. Patients who have hypertriglyceridemia may be at significant risk for CVD even if low-density lipoprotein cholesterol levels are at goal, and therefore warrant treatment that optimizes diet, reduces overweight, and promotes regular exercise. High-risk patients with hypertriglyceridemia, such as those with diabetes, CVD, or metabolic syndrome, may benefit from additional drug treatment aside from a statin to address other lipid abnormalities. In this discussion, we review the role of hypertriglyceridemia and its associated atherogenic lipoproteins in the pathogenesis of atherosclerosis, the relevance of a high TG level as a predictor of CVD, the cardiovascular outcomes from TG-lowering intervention trials, and the current guidelines for treating hypertriglyceridemia.
\end{abstract}

\section{Keywords}

Atherogenic dyslipidemia; Atherogenic remnant lipoproteins; Atherosclerosis; Cardiovascular disease; Chylomicron remnants; Lipoprotein lipase; Risk factor; Triglycerides; Triglyceride-rich lipoproteins; Very low density lipoproteins

\section{Introduction}

With a growing epidemic of childhood and adult obesity, insulin resistance, and type 2 diabetes, atherosclerotic cardiovascular disease (CVD) remains the leading cause of death and disability in the Western world, affecting over 13.2 million Americans [1]. Among risk factors for CVD, it is estimated by the NHANES 1999 to 2008 that the overall prevalence of hypertriglyceridemia in the adult population in the United States is 31\% [2]. More so, the prevalence of triglyceride (TG) levels above $150 \mathrm{mg} / \mathrm{dL}$ is nearly twice as high in subjects with metabolic syndrome $[3,4]$. For this reason, comprehensive evaluation and management of CVD must address hypertriglyceridemia and the dyslipidemic states associated with it.

Although elevated low-density lipoprotein cholesterol (LDL-C) is well established as a major predictor of coronary heart disease (CHD) risk and has been the primary target for

Corresponding author: Frank M. Sacks, fsacks@ @sph.harvard.edu. Beatriz G. Talayero, btalayer@hsph.harvard.edu, Harvard School of Public Health 665 Huntington Avenue, Building 1, Room 203, Boston, MA, 02115, USA.

Disclosure

Conflicts of interest: B.G. Talayero: none; F.M. Sacks: has board membership with R3i Foundation; has been a consultant for Abbott, Amgen, Pfizer, Roche, Merck, Eli Lilly, ISIS, and Genzyme; has given expert testimony for Abbott and Par; has received grant support from ISIS; and has received honoraria from Abbott. 
lipid-lowering strategies by the US NCEP [2], evidence suggests that an elevated TG level is also an independent risk factor [5-7]. Large-scale, randomized, prospective trials involving patients with CHD have shown that treatment with statins reduces the relative risk of cardiovascular deaths, nonfatal myocardial infarction, and stroke [8]. However, in many cases the continuing risk despite optimal LDL-C reduction on statin monotherapy remains high and may result in part from residual atherogenic dyslipidemia. This means that in addition to the critical role that LDL-C plays in atherosclerosis, there is significant contribution from hypertriglyceridemia and its associated conditions.

High TG levels are markers for atherogenic lipoproteins, particularly important in patients with insulin resistant syndromes such as type 2 diabetes mellitus and metabolic syndrome who commonly present with combined dyslipidemia characterized by fasting and postprandial hypertriglyceridemia, low high-density lipoprotein cholesterol (HDL-C) levels, small LDL and HDL particles, and accumulation of partially metabolized chylomicrons (CMs) and very low density lipoproteins (VLDLs), the so-called remnant particles rich in apolipoprotein (apo) C-III and cholesterol. These patients are at significant risk for CVD even if LDL-C levels are at goal, and therefore warrant treatment that goes beyond the use of statins to address other lipid abnormalities.

In this discussion, we review the role of TG in the pathogenesis of atherosclerosis, the relevance of a high TG level as a predictor of CHD, the cardiovascular outcomes from TGlowering intervention trials, and the current guidelines for treating hypertriglyceridemia.

\section{Triglycerides and Atherogenesis}

TGs, as far as is currently known, are not directly atherogenic but represent an important biomarker of CVD risk because of their association with atherogenic remnant particles and apo C-III, a proinflammatory, proatherogenic protein found on all classes of the plasma lipoproteins. Several species of triglyceride-rich lipoproteins (TRLs) including VLDL and VLDL remnants, as well as CM remnants appear to promote atherogenesis independently of LDL. Remnant species result from partial hydrolysis by lipoprotein lipase (LPL) of TRLs of hepatic and intestinal origin that have picked up cholesterol esters from HDL through the action of cholesterol ester transfer protein [9]. Similar to oxidized LDL, these cholesterolenriched, TG-poor species are subject to endothelial accumulation and uptake by macrophages to form foam cells $[10,11]$. Foam cells promote fatty streak formation, the precursor of atherosclerotic plaque.

To avoid the atherogenic inflammatory cascade, TRL remnants must be cleared from plasma and metabolized by the liver before endothelial accumulation occurs. However, hypertriglyceridemic states are associated with increased VLDL production and delayed VLDL clearance from circulation [12, 13•]. High liver secretion of large TG-rich VLDL that contains apo C-III is a common finding in hypertriglyceridemia and in some cases has been associated with insulin resistance [14]. In addition, delayed clearance of all apo B lipoproteins, including VLDL, has been attributed to different mechanisms such as apo CIII-mediated inhibition of apo E and apo B-100 binding to hepatic receptors and proteoglycan; reduced activity of LPL, hepatic TG lipase, or novel receptors such as GPIanchored HDL-binding protein 1 (GPIHBP1) or proteoglycan [13•]; and finally, reduced apo $\mathrm{E}$ and apo $\mathrm{E}$ to C-III ratio reflecting reduced ability of the lipoproteins to be taken up by the liver. Similarly, CMs are taken up by the liver via LDL receptors or LDL receptor-related proteins and unless their TG core is removed they are not considered atherogenic due to their very large size, which slows entry into the arterial intima. It is the resulting CM remnants that are atherogenic, presumably because they are sufficiently small to pass through the endothelial cell barrier to the arterial intima [10]. Hepatic lipase also plays a role 
in remnant removal [15] and its deficiency is associated with reduced TRL remnant clearance.

TRLs have been associated with coronary atherosclerosis in human observational studies [16]. Furthermore, studies on experimental models have described mechanisms by which TRLs and their remnants produce numerous proatherogenic responses including enhanced recruitment and attachment of monocytes through the action of endothelial- and macrophage-derived inflammatory proteins such as tumor necrosis factor- $\alpha$ (TNF- $\alpha$ ), interleukin (IL)-1 $\beta$, monocyte chemotactic protein-1, intercellular adhesion molecule-1, and matrix metalloproteinase-3 [17]; increased expression of adhesion molecules and decreased artery flow-mediated vasodilation, both of which are implicated in endothelial dysfunction and thought to be an early sign of atherosclerosis [18]; and direct vascular cytotoxicity via lipolytic byproducts [19]. TRLs may also act to suppress the atheroprotective and antiinflammatory effects of HDL by blocking sterol efflux from monocytes and macrophages $[20,21]$.

Atherogenicity of TRLs has been linked to their apo C-III content. VLDL and LDL that have apo C-III stimulate a range of processes that are involved in atherosclerosis including activation of both monocytes and endothelial cells to produce adhesion molecules and proinflammatory transcription factors that induce inflammatory mediators TNF- $\alpha$ and IL-1 $\beta$ [22]; activation of proinflammatory transcription factors nuclear factor $-\kappa \mathrm{B}$, rhoA, and protein kinase $C$ [22]; activation of insulin resistance pathways in endothelial cells reducing their production of nitric oxide causing vascular dysfunction [18]; and increased oxidation and proteoglycan binding [23]. Apo C-III itself confers on VLDL these effects, although the lipids in VLDL may have additional proinflammatory effects on vascular cells. Furthermore, a mutation in APOC3 was recently identified in association with low TG levels, reduced coronary artery calcification, and suggestion of familial longevity [24].

Also of interest, the activity of LPL and other endothelial lipases has been the subject of many studies. On one hand, lipolysis is per se antiatherogenic due to its TG-lowering activity. LPL itself can attach to TRLs during lipolysis at the arterial endothelium and enhance binding of these lipoproteins to hepatic receptors and clearance from circulation [25]. On the other hand, various lipases have been implicated in atherosclerosis by virtue of their direct role in the regulation of lipids and lipoproteins and their role in vascular pathways affecting the adhesion molecule recruitment and remodeling observed with prolonged exposure of endothelium to lipolysis products [26]. Specifically, LPL expressed in macrophages appears to have proatherogenic effects independent of plasma lipoproteins [27], and the resulting lipolytic products of TRLs have been shown to produce direct cytotoxicity and apoptosis in isolated macrophages [28].

Increased levels of prothrombotic factors, such as fibrinogen and plasminogen activator inhibitors, as well as proinflammatory molecules such as C-reactive protein, TNF- $\alpha$, fibrinogen, and IL-6, have been observed in obese subjects and patients with high TG [29, 30]. Postprandial TRLs increase the expression of proinflammatory genes (eg, IL-6, intercellular adhesion molecule-1, vascular cell adhesion molecule-1, and monocyte chemotactic protein-1), particularly after a high-fat meal [31].

\section{Triglycerides and Risk for CHD}

Individual epidemiologic studies have differed regarding the strength of association between hypertriglyceridemia and CHD, specifically after adjusting for the presence of associated risk factors such as insulin resistance and HDL-C levels, and are further complicated when considering the skewed distribution and high variability of TG levels [32]. Therefore, meta- 
analysis has been crucial to distinguish TG as an independent risk factor from a risk marker of associated conditions such as those in the metabolic syndrome.

In 2007, Sarwar et al. [7] performed a large meta-analysis of 29 prospective studies from Western populations and reported an odds ratio of 1.7 (95\% CI, 1.6-1.9) comparing the risk of CHD for those in the upper to lower tertiles of the TG distribution after adjusting for other risk factors. Interestingly, in contrast to an earlier study by Hokanson and Austin [5], this study found no difference between men and women in the strength of association. A similar odds ratio was reported in a meta-analysis that included data from 26 prospective studies in Asian and Pacific populations [33].

In contrast, the Emerging Risk Factors Collaboration study [34] collected data from 68 prospective studies and found that the strong stepwise association observed between elevated TG levels and CVD and stroke lost significance once HDL-C and non-HDL-C levels were included in multiple variable models, concluding that TG measurement provided no additional information about vascular risk.

Recent case-control studies [35•, 36•] investigating the relative contributions of TGs and HDL-C to CHD have found that the residual risk after reduction of LDL-C to guidelinerecommended levels in patients with atherogenic dyslipidemia is strongly associated with both high TG levels and low HDL-C and the combination is at least additive to the odds ratio, and possibly synergistic. The high residual risk associated with TGs in the setting of optimal LDL-C levels might be related to a greater concentration of apo C-III containing lipoproteins [35•]. These findings contribute to the rationale for considering high TG and low HDL-C levels, especially when they occur together, in quantifying the risk level to select the type and intensity of treatment.

Studies of secondary prevention of CHD [35•, 37, 38] found that a TG level below $150 \mathrm{mg} /$ $\mathrm{dL}$ was independently associated with a lower risk of CHD events in patients receiving highintensity statin treatment, which produced especially low LDL-C concentrations.

Specifically, data from the PROVE IT-TIMI 22 trial comparing standard and high-intensity statin therapy after acute coronary syndrome (ACS) observed a $1.6 \%$ lower risk of the composite end point (death, myocardial infarction, and recurrent ACS) for each 10-mg/dL decline in on-treatment TG after adjusting for LDL-C and other covariates [38].

Before these recent epidemiological studies were published, and before compelling mechanistic information from basic science on atherogenicity of TRLs became available, the assignment of TG level as an independent risk factor and a causal factor in promoting CVD remained debatable. Therefore, the NCEP ATP III, published in 2001 and remaining the current US guidelines, determined that there was insufficient evidence to regard TG as an independent coronary risk factor in Western populations [2]. However, more recent data add confidence to the conclusion that TG levels appear to provide unique information as a biomarker of risk.

\section{Measuring Cardiovascular Risk}

The 2011 American Heart Association (AHA) scientific statement on TG and CVD [39] suggested the following new designations regarding the measurement of TG levels: 1) screening for hypertriglyceridemia by using nonfasting TG levels. Nonfasting levels greater than $200 \mathrm{mg} / \mathrm{dL}$ require further follow-up with fasting TG levels; 2) optimal fasting TG levels, defined as less than $100 \mathrm{mg} / \mathrm{dL}$, are a parameter of metabolic health;3) fasting samples are used to designate borderline high (150-199 mg/dL), high (200-499 mg/dL), and very high (> $500 \mathrm{mg} / \mathrm{dL}$ ) TG levels. The use of nonfasting TG levels stems from their proposed superiority as predictors of incident CVD compared with fasting TGs [40, 41]. 
Current NCEP ATP III guidelines advocate the use of non-HDL-C as a secondary lipid target for therapy after LDL-C if TG level is above $200 \mathrm{mg} / \mathrm{dL}$ [2]. Non-HDL-C measures the cholesterol concentration of all atherogenic apo B-containing lipoproteins, including LDL-C, VLDL-C, intermediate-density lipoprotein-cholesterol, lipoprotein(a), CM, and CM remnants combined; and has been found to predict cardiovascular risk better than LDL-C [42].

Alternatively, apo B has been proposed as an excellent predictor of CHD, generally superior to LDL-C and even to non-HDL-C [43-45]. One reason for the superiority of apo B is that, in hypertriglyceridemia, LDL contains less cholesterol than normal. Apo B counts each LDL the same whatever its cholesterol content. The rationale for measuring apo B is that the concentration of VLDL and LDL may be more relevant to atherosclerosis than how much cholesterol they carry. Apo B is not affected acutely by diet and it can quantify risk in hypertriglyceridemia. However, ATP III guidelines favor the use of non-HDL-C rather than apo B because of limited availability of apo B assays in clinical laboratories, compounded by the lack of a national standardization program and higher cost than for non-HDL-C [2]. Nevertheless, in view of additional data and in the presence of standardization that has accrued since ATP III was released in 2001, a panel of international experts has recommended a revision of this assessment [46].

\section{Cardiovascular Outcomes After Triglyceride Reduction}

In contrast to the clear relationship between LDL-C lowering and CHD risk reduction, drug intervention trials that reduce TG concentrations have not reached consistent conclusions regarding the independent relevance of TGs to CHD because these interventions also influence several lipid fractions and in some cases may have other antiatherogenic properties such as direct effects on plaque remodeling.

Statins are the most effective lipid-lowering drugs used in clinical practice and are widely used to target LDL-C levels in primary and secondary cardiovascular prevention. They are effective in lowering non-HDL-C, mainly because of their LDL-lowering action. Statins also lower TG levels in plasma [47] and reduce concentrations of apo C-III [48]. The higher the baseline TG level the greater the TG-lowering effect. Trials of statin monotherapy found that increased baseline TG levels predicted increased CVD [48-52] and that statins reduced CVD in patients who had high TGs $[8,53]$. This provides a rationale for statin therapy in patients with mild to moderate hypertriglyceridemia.

Fibrates have been tested in several large, randomized trials involving diverse populations [54-58]. The most pronounced effect of fibrates is to lower plasma TG. Although results of the individual trials varied for their primary outcomes, post hoc analysis of these trials showed that the relative risk reduction for CVD events was statistically significant in patients with atherogenic dyslipidemia (high TGs and/or low HDL-C), and nominally greater than in those without these conditions [59-62, 63•]. However, it is not proven that the decrease in TG level observed with fibrate treatment caused the reduction in CVD.

The ACCORD trial evaluating the benefit of adding fenofibrate to simvastatin therapy concluded that the use of fenofibrate in patients with diabetes did not reduce the rate of CHD events. However, the ACCORD Lipid subgroup analysis, together with previous fibrate trials, support the hypothesis that fibrate therapy may reduce cardiovascular events among patients with clinically significant dyslipidemia (defined as TG level $>200 \mathrm{mg} / \mathrm{dL}$ and HDL-C level < $40 \mathrm{mg} / \mathrm{dL}$ ) [63•].

This finding is further substantiated by a recently published systematic review and metaanalysis of 18 trials evaluating the effects of fibrates on cardiovascular outcomes, which 
reported a $10 \%$ relative risk reduction $(95 \% \mathrm{CI}, 0-18)$ for major cardiovascular events $(P=$ $0.048)$ and a $13 \%$ relative risk reduction $(7-19)$ for coronary events $(P<0.0001)$. More so, subgroup analysis demonstrated that fibrates significantly reduced cardiovascular events in individuals with hypertriglyceridemia alone or in combination with low HDL-C [64•].

Another drug approved for the treatment of dyslipidemias is nicotinic acid, a form of niacin. Niacin favorably affects levels of all lipoprotein fractions associated with atherosclerosis, decreasing apo B-containing lipoproteins, including lipoprotein(a), while increasing hepatic apo A-1 synthesis and reducing HDL clearance from the circulation. Although most noted for its potent effects on raising HDL-C levels, niacin also lowers TGs [65].

The Coronary Drug Project is the only randomized controlled trial of niacin as a sole agent for coronary prevention. During this 5-year, double-blind, placebo-controlled trial conducted in the 1970s, niacin reduced the incidence of nonfatal myocardial infarction when compared with placebo at 5 years [66] and reduced all-cause mortality on extended follow-up [67]. However, there was no significant correlation between change in serum TG level and mortality [67].

More recently, the AIM-HIGH: Niacin Plus Statin to Prevent Vascular Events trial [68] was the first large study to assess the clinical benefit associated with the addition of extendedrelease niacin to an intensive statin \pm ezetimibe regimen when both groups were treated to an aggressive LDL-C target of 40 to $80 \mathrm{mg} / \mathrm{dL}$. At 32-month follow-up, the trial found that although HDL-C levels were increased by $22 \%$ and TG levels lowered by $25 \%$ in the intervention arm, the expected reduction in CVD events was not observed. This trial was therefore stopped 18 months short of completion in April 2011.

Lastly, omega-3 polyunsaturated fatty acids (PUFAs) containing eicosapentaenoic acid (EPA) and docosahexaenoic acid have dose-dependent TG-lowering effects resulting from a variety of mechanisms including decreased VLDL secretion and improved VLDL TG clearance [69]. Similar to statins, the TG-lowering effect of omega-3 PUFAs is greater for patients with hypertriglyceridemia [70]. At a dose of $4 \mathrm{~g} /$ day, TG concentrations decrease by $25 \%$ to $30 \%$, with accompanying increases of $5 \%$ to $10 \%$ in LDL-C and $1 \%$ to $3 \%$ in HDL$\mathrm{C}$ [71]. Although large clinical trials have reported a reduction in major cardiac events and sudden cardiac death with omega-3 fatty acid dietary intake or supplementation [72], these cardiovascular benefits are thought to be primarily a result of effects on cardiac rhythm rather than on lipids. The JELIS [73] found that $1800 \mathrm{mg} /$ day of EPA supplementation combined with low-dose statin decreased the rate of major coronary events when compared with statin monotherapy. However, TG level reduction in this group was minimal suggesting that the observed risk reduction was not a TG-mediated effect. The clinical efficacy of high doses of omega-3 PUFA is yet to be established through a well-designed randomized controlled trial to determine the extent to which TG and non-HDL-C lowering through supplementation with marine-derived omega-3 PUFA improves CVD outcomes beyond standard-of-care therapy.

Thus, the possible benefit of residual risk reduction suggests a role for treatment of persistently high TG concentrations in statin-treated patients, especially with fibrates because of their efficacy in lowering plasma TG level and their reduction of CVD in patients who have hypertriglyceridemia.

\section{Guidelines for Treatment of Hypertriglyceridemia}

Current ATP III guidelines [2] advocate treatment of elevated TG levels according to their severity and the levels of other lipids (Table 1). The new NECP ATP IV guidelines for treatment of hypertriglyceridemia are expected to be released in the fall of 2011. 
TG levels are markedly affected by overweight and body fat distribution, specifically, excess visceral adiposity [74]. For this reason, treatment of hypertriglyceridemia focuses on weight loss. Reduced carbohydrate diets lower TG independently of changes in body weight. Replacement of some dietary carbohydrate with unsaturated fat is most effective in lowering TG. However, in context of sustained weight loss, high-carbohydrate and lowcarbohydrate diets lower plasma TG [75, 76]. Further optimization of TG levels through lifestyle modifications can be achieved with aerobic exercise. Exercise is most effective in lowering TGs when baseline levels are elevated, activity is moderate to intensive, and total caloric intake is reduced [77]. Taken together, reductions of up to $40 \%$ in TG levels may be attained through intensive therapeutic lifestyle changes (Table 2).

Aside from lifestyle changes, further treatment with lipid-lowering drugs, such as statins, fibrates, nicotinic acid, or omega-3 fatty acids, may be warranted and should be considered to help achieve non-HDL-C targets in patients with hypertriglyceridemia. The efficacies of pharmacologic interventions on TG level reduction vary depending on the agent used and the pretreatment TG level (Table 2). The most recent AHA scientific statement on TG and CVD [46] concludes 1) in patients with hypertriglyceridemia, statin monotherapy may be beneficial in the setting of an LDL-C level that merits treatment; 2) fibrate monotherapy may be beneficial in patients with high TG levels, low HDL-C, or both; 3) high-risk statintreated patients who continue to have elevated TG levels display a residual risk for CVD that is likely a result of the multiple metabolic abnormalities observed in atherogenic dyslipidemia; 4) there is limited data on the potential benefit of adding a second drug in these high-risk patients. Additional clinical outcome trials are necessary to evaluate this benefit.

In line with the second recommendation of the AHA statement on TG, other health organizations such as the Residual Risk Reduction Initiative (R3I) [78] recommend further therapeutic intervention that targets all lipid risk factors including hypertriglyceridemia.

\section{Conclusions}

Hypertriglyceridemia is a prevalent risk factor for CVD and increasingly important in the setting of current obesity and insulin resistance epidemics. Recent data add confidence to the conclusion that TG levels appear to provide unique information as a biomarker of CVD risk because of their association with atherogenic lipoproteins and apolipoproteins, especially apo C-III. Another surrogate marker of CHD risk is non-HDL-C, which combines the cholesterol levels found in LDL-C and TG-rich lipoproteins. Lowering non-HDL-C has clearly been associated with benefit, and has been designated as the second lipid target after LDL-C level by the NCEP ATP III guidelines. Although there is no rigorous outcome data definitely proving that reduction in TG level reduces CVD, current epidemiologic data and clinical trial results support an association between elevated TG and CVD risk. The possible benefit of residual risk reduction through therapeutic interventions that target all lipid risk factors including hypertriglyceridemia suggests a role for treatment of persistently high TG concentrations in high-risk, statin-treated patients. Additional clinical outcome trials are necessary to fully evaluate this benefit.

\section{Clinical Trial Acronyms}

ACCORD-Action to Control Cardiovascular Risk in Diabetes; AIM-HIGHAtherothrombosis Intervention in Metabolic syndrome with Low HDL/High Triglycerides: Impact on Global Health Outcomes; JELIS-Japan EPA Lipid Intervention Study; NCEP ATP III-National Cholesterol Education Program Adult Treatment Panel III; NHANES- 
National Health and Nutrition Examination Survey; PROVE IT-TIMI 22-Pravastatin or Atorvastatin Evaluation and Infection Therapy-Thrombolysis in Myocardial Infarction 22.

\section{References and Recommended Reading}

Papers of particular interest, published recently, have been highlighted as:

- Of importance

- Of major importance

1. Lloyd-Jones D, Adams RJ, Brown TM, et al. Heart disease and stroke statistics--2010 update: a report from the American Heart Association. Circulation. 2010; 121(7):e46-e215. [PubMed: 20019324]

2. National Cholesterol Education Program (NCEP) Expert Panel on Detection, Evaluation, and Treatment of High Blood Cholesterol in Adults (Adult Treatment Panel III). Third Report of the National Cholesterol Education Program (NCEP) Expert Panel on Detection, Evaluation, and Treatment of High Blood Cholesterol in Adults (Adult Treatment Panel III). Circulation. 2002; 106(25):3143-421. [PubMed: 12485966]

3. Ford ES, Giles WH, Dietz WH. Prevalence of the metabolic syndrome among US adults: findings from the third National Health and Nutrition Examination Survey. JAMA. 2002; 287(3):356-9. [PubMed: 11790215]

4. Alexander CM, Landsman PB, Teutsch SM, et al. NCEP-defined metabolic syndrome, diabetes, and prevalence of coronary heart disease among NHANES III participants age 50 years and older. Diabetes. 2003; 52(5):1210-4. [PubMed: 12716754]

5. Hokanson JE, Austin MA. Plasma triglyceride level is a risk factor for cardiovascular disease independent of high-density lipoprotein cholesterol level: A meta-analysis of population-based prospective studies. J Cardiovasc Risk. 1996; 3(2):213-9. [PubMed: 8836866]

6. Schulte H, Cullen P, Assmann G. Obesity, mortality and cardiovascular disease in the Münster Heart Study (PROCAM). Atherosclerosis. 1999; 144(1):199-209. [PubMed: 10381293]

7. Sarwar N, Danesh J, Eiriksdottir G, et al. Triglycerides and the risk of coronary heart disease: 10,158 incident cases among 262,525 participants in 29 Western prospective studies. Circulation. 2007; 115:450-8. [PubMed: 17190864]

8. Baigent C, Keech A, Kearney PM, et al. Cholesterol Treatment Trialists Collaborators. Efficacy and safety of cholesterol-lowering treatment: prospective meta-analysis of data from 90,056 participants in 14 randomised trials of statins. Lancet. 2005; 366(9493):1267-78. [PubMed: 16214597]

9. Brewer HB Jr. Hypertriglyceridemia: changes in the plasma lipoproteins associated with an increased risk of cardiovascular disease. Am J Cardiol. 1999; 83(9B):3F-12F.

10. Gianturco SH, Ramprasad MP, Song R, et al. Apolipoprotein B-48 or its apolipoprotein B-100 equivalent mediates the binding of triglyceride rich lipoproteins to their unique human monocytemacrophage receptor. Arterioscler Thromb Vasc Biol. 1998; 18 (6):968-976. [PubMed: 9633939]

11. Botham KM, Moore EH, De Pascale C, et al. The induction of macrophage foam cell formation by chylomicron remnants. Biochem Soc Trans. 2007; 35:454-8. [PubMed: 17511626]

12. Ooi EM, Barrett PH, Chan DC, et al. Apolipoprotein C-III: understanding an emerging cardiovascular risk factor. Clin Sci. 2008; 114(10):611-24. [PubMed: 18399797]

13. Zheng C, Furtado J, Khoo C, et al. Apolipoprotein C-III and the metabolic basis for hypertriglyceridemia and the dense LDL phenotype. Circulation. 2010; 121(15):1722-34. These results support a central role for apo C-III in metabolic defects leading to hypertriglyceridemia and the dense LDL phenotype. In hypertriglyceridemia, TG-rich lipoprotein metabolism shifts from an apo E dominated system to an apo C-III dominated system characterized by reduced clearance of TG-rich lipoproteins and their conversion to dense LDL. [PubMed: 20368524]

14. Kamagate A, Dong HH. FoxO1 integrates insulin signaling to VLDL production. Cell Cycle. 2008; 7(20):3162-70. [PubMed: 18927507]

15. Cooper AD. Hepatic uptake of chylomicron remnants. J Lipid Res. 1997; 38(11):2173-92. [PubMed: 9392416] 
16. Colhoun HM, Otvos JD, Rubens MB, et al. Lipoprotein subclasses and particle sizes and their relationship with coronary artery calcification in men and women with and without type 1 diabetes. Diabetes. 2002; 51(6):1949-56. [PubMed: 12031985]

17. Van Eck M, Zimmermann R, Groot PH, et al. Role of macrophage-derived lipoprotein lipase in lipoprotein metabolism and atherosclerosis. Arterioscler Thromb Vasc Biol. 2000; 20(9):E53-E62. [PubMed: 10978269]

18. Kawakami A, Osaka M, Tani M, et al. Apolipoprotein CIII links hyperlipidemia with vascular endothelial function. Circulation. 2008; 118(7):731-42. [PubMed: 18663085]

19. Wang L, Gill R, Pedersen TL, et al. Triglyceride-rich lipoprotein lipolysis releases neutral and oxidized FFAs that induce endothelial cell inflammation. J Lipid Res. 2009; 50(2):204-213. [PubMed: 18812596]

20. Palmer AM, Murphy N, Graham A. Triglyceride-rich lipoproteins inhibit cholesterol efflux to apolipoprotein (apo) A1 from human macrophage foam cells. Atherosclerosis. 2004; 173(1):2738. [PubMed: 15177121]

21. Patel S, Puranik R, Nakhla S, et al. Acute hypertriglyceridaemia in humans increases the triglyceride content and decreases the anti-inflammatory capacity of high density lipoproteins. Atherosclerosis. 2009; 204(1):424-428. [PubMed: 19111829]

22. Kawakami A, Aikawa M, Alcaide P, et al. Apolipoprotein CIII induces expression of vascular cell adhesion molecule-1 in vascular endothelial cells and increases adhesion of monocytic cells. Circulation. 2006; 114(7):681-7. [PubMed: 16894036]

23. Hiukka A, Stahlman M, Pettersson C, et al. ApoCIII-Enriched LDL in type 2 diabetes displays altered lipid composition, increased susceptibility for sphingomyelinase, and increased binding to biglycan. Diabetes. 2009; 58(9):2018-26. [PubMed: 19502413]

24. Pollin TI, Damcott CM, Shen H, et al. A null mutation in human APOC3 confers a favorable plasma lipid profile and apparent cardioprotection. Science. 2008; 322(5908):1702-5. [PubMed: 19074352]

25. Zheng C, Murdoch S, Brunzell J, et al. Lipoprotein Lipase Bound to Apolipoprotein B Lipoproteins Accelerates Clearance of Postprandial Lipoproteins in Humans. Arterioscler Thromb Vasc Biol. 2006; 26(4):891-6. [PubMed: 16410459]

26. Goldberg IJ. Lipoprotein lipase and lipolysis: central roles in lipoprotein metabolism and atherogenesis. J Lipid Res. 1996; 37(4):693-707. [PubMed: 8732771]

27. Olivecrona G, Olivecrona T. Triglyceride lipases and atherosclerosis. Curr Opin Lipidol. 2010; 21:409-15. [PubMed: 20683326]

28. Wehinger A, Tancevski I, Schgoer W, et al. Phospholipid transfer protein augments apoptosis in THP-1-derived macrophages induced by lipolyzed hypertriglyceridemic plasma. Arterioscler Thromb Vasc Biol. 2007; 27:908-15. [PubMed: 17272752]

29. Georgieva AM, Cate HT, Keulen ET, et al. Prothrombotic markers in familial combined hyperlipidemia: evidence of endothelial cell activation and relation to metabolic syndrome. Atherosclerosis. 2004; 75(2):345-51. [PubMed: 15262191]

30. Sutherland JP, McKinley B, Eckel RH. The metabolic syndrome and inflammation. Metab Syndr Relat Disord. 2004; 2(2):82-104. [PubMed: 18370640]

31. Norata GD, Grigore L, Raselli S, et al. Post-prandial endothelial dysfunction in hypertriglyceridemic subjects: molecular mechanisms and gene expression studies. Atherosclerosis. 2007; 193:321-7. [PubMed: 17055512]

32. Jacobs DR, Barrett-Connor E. Retest reliability of plasma cholesterol and triglyceride: the Lipid Research Clinics Prevalence Study. Am J Epidemiol. 1982; 116:878-885. [PubMed: 7148814]

33. Asia Pacific Cohort Studies Collaboration. Serum triglycerides as a risk factor for cardiovascular diseases in the Asia-Pacific region. Circulation. 2004; 110:2678-2686. [PubMed: 15492305]

34. Di Angelantonio E, Sarwar N, Perry P, et al. Emerging Risk Factors Collaboration. Major lipids, apolipoproteins, and risk of vascular disease. JAMA. 2009; 302:1993-2000. [PubMed: 19903920]

35. Carey VJ, Bishop L, Laranjo N, et al. Contribution of High Plasma Triglycerides and Low HighDensity Lipoprotein Cholesterol to Residual Risk of Coronary Heart Disease After Establishment of Low-Density Lipoprotein Cholesterol Control. Am J Cardiol. 2010; 106:757-63. This study highlights a strong and synergistic contribution of high TG and low HDL-C levels to CHD when 
LDL-C is at goal. These results suggest that lowering TGs may have greater potential for clinical benefit when LDL-C is low. [PubMed: 20816113]

36•. Assmann G, Cullen P, Schulte H. Non-LDL-related dyslipidaemia and coronary risk: a casecontrol study. Diab Vasc Dis Res. 2010; 7(3):204-12. Findings from this study suggest that residual cardiovascular risk associated with hypertriglyceridemia is greatest in persons in whom LDL-C concentration is in a low target range. [PubMed: 20643700]

37. Sacks FM, Tonkin AM, Craven T, et al. Coronary heart disease in patients with low LDLcholesterol: benefit of pravastatin in diabetics and enhanced role for HDL-cholesterol and triglycerides as risk factors. Circulation. 2002; 105:1424-8. [PubMed: 11914249]

38. Miller M, Cannon CP, Murphy SA, et al. Impact of triglyceride levels beyond low-density lipoprotein cholesterol after acute coronary syndrome in the PROVE IT-TIMI 22 trial. J Am Coll Cardiol. 2008; 51:724-30. [PubMed: 18279736]

39. Miller M, Stone NJ, Ballantyne C, et al. Triglycerides and Cardiovascular Disease: A Scientific Statement From the American Heart Association. Circulation. 2011; 123:2292-333. [PubMed: 21502576]

40. Nordestgaard BG, Benn M, Schnohr P, et al. Nonfasting triglycerides and risk of myocardial infarction, ischemic heart disease, and death in men and women. JAMA. 2007; 298:299-308. [PubMed: 17635890]

41. Bansal S, Buring JE, Rifai N, et al. Fasting compared with nonfasting triglycerides and risk of cardiovascular events in women. JAMA. 2007; 298:309-316. [PubMed: 17635891]

42. Miller M, Ginsberg HN, Schaefer EJ. Relative atherogenicity and predictive value of non-highdensity lipoprotein cholesterol for coronary heart disease. Am J Cardiol. 2008; 101:1003-8. [PubMed: 18359322]

43. Thompson A, Danesh J. Associations between apolipoprotein B, apolipoprotein AI, the apolipoprotein B/AI ratio and coronary heart disease: a literature-based meta-analysis of prospective studies. J Intern Med. 2006; 259(5):481-92. [PubMed: 16629854]

44. Pischon T, Girman CJ, Sacks FM, et al. Non-high-density lipoprotein cholesterol and apolipoprotein B in the prediction of coronary heart disease in men. Circulation. 2005; 112:337583. [PubMed: 16316964]

45. Sniderman A, Williams K, Cobbaert C. ApoB versus non-HDL-C: what to do when they disagree. Curr Atheroscler Rep. 2009; 11:358-63. [PubMed: 19664379]

46. Barter PJ, Ballantyne CM, Carmena R, et al. Apo B versus cholesterol in estimating cardiovascular risk and in guiding therapy: report of the thirty-person/ten-country panel. J Intern Med. 2006; 259:247-58. [PubMed: 16476102]

47. Stein EA, Lane M, Laskarzewski P. Comparison of statins in hypertriglyceridemia. Am J Cardiol. 1998; 81:66B-69B.

48. Sacks FM, Alaupovic P, Moye LA. Effect of pravastatin on apolipoproteins B and C-III in verylow-density lipoproteins and low-density lipoproteins. Am J Cardiol. 2002; 90(2):165-7. [PubMed: 12106851]

49. Girman CJ, Rhodes T, Mercuri M, et al. 4S Group and the AFCAPS/TexCAPS Research Group. The metabolic syndrome and risk of major coronary events in the Scandinavian Simvastatin Survival Study (4S) and the Air Force/Texas Coronary Atherosclerosis Prevention Study (AFCAPS/TexCAPS). Am J Cardiol. 2004; 93:136-141. [PubMed: 14715336]

50. Pyörälä K, Pedersen TR, Kjekshus J, et al. Cholesterol lowering with simvastatin improves prognosis of diabetic patients with coronary heart disease: a subgroup analysis of the Scandinavian Simvastatin Survival Study (4S) [published correction appears in Diabetes Care.1997;20:1048]. Diabetes Care. 1997; 20:614-620. [PubMed: 9096989]

51. Sacks FM, Alaupovic P, Moye LA, et al. VLDL, apolipoproteins B, CIII, and E, and risk of recurrent coronary events in the Cholesterol and Recurrent Events (CARE) trial. Circulation. 2000; 102:1886-1892. [PubMed: 11034934]

52. Kastelein JJP, van der Stieg W, Holme I, et al. Lipids, apolipoproteins, and their ratios in relation to cardiovascular events with statin treatment. Circulation. 2008; 117:3002-9. [PubMed: $18519851]$ 
53. Pfeffer MA, Sacks FM, Moyé LA, et al. Influence of baseline lipids on effectiveness of pravastatin in the CARE Trial: Cholesterol And Recurrent Events. J Am Coll Cardiol. 1999; 33:125-130. [PubMed: 9935018]

54. Ginsberg HN, Elam MB, Lovato LC, et al. Effects of combination lipid therapy in type 2 diabetes mellitus. The ACCORD Study Group. N Engl J Med. 2010; 362:1563-74. [PubMed: 20228404]

55. Scott R, O'Brien R, Fulcher G, et al. Effects of fenofibrate treatment on cardiovascular disease risk in 9,795 individuals with type 2 diabetes and various components of the metabolic syndrome: the Fenofibrate Intervention and Event Lowering in Diabetes (FIELD) study. Diabetes Care. 2009; 32:493-8. [PubMed: 18984774]

56. The BIP Study Group. Secondary prevention by raising HDL cholesterol and reducing triglycerides in patients with coronary artery disease: the Bezafibrate Infarction Prevention (BIP) study. Circulation. 2000; 102:21-7. [PubMed: 10880410]

57. Manninen V, Tenkanen L, Koskinen P, et al. Joint effects of serum triglyceride and LDL cholesterol and HDL cholesterol concentrations on coronary heart disease risk in the Helsinki Heart Study: implications for treatment. Circulation. 1992; 85:37-45. [PubMed: 1728471]

58. Robins SJ, Collins D, Wittes JT, et al. Relation of gemfibrozil treatment and lipid levels with major coronary events: VA-HIT: a randomized controlled trial. JAMA. 2001; 285:1585-91. [PubMed: 11268266]

59. Tenkanen L, Mantarri M, Manninen V. Some coronary risk factors related to the insulin resistance syndrome and treatment with gemfibrozil: experience from the Helsinki Heart Study. Circulation. 1995; 92:1779-85. [PubMed: 7671361]

60. Rubins HB, Robins SJ, Collins D, et al. Diabetes, plasma insulin, and cardiovascular disease: subgroup analysis from the Department of Veterans Affairs high-density lipoprotein intervention trial (VA-HIT). Arch Intern Med. 2002; 162:2597-604. [PubMed: 12456232]

61. Tenenbaum A, Motro M, Fisman EZ, et al. Bezafibrate for the secondary prevention of myocardial infarction in patients with metabolic syndrome. Arch Intern Med. 2005; 165:1154-60. [PubMed: 15911729]

62. Scott R, d'Emden M, Best J, et al. on behalf of the FIELD Investigators. Features of metabolic syndrome identify individuals with type 2 diabetes mellitus at high risk for cardiovascular events and greater absolute benefits of fenofibrate. Circulation. 2007; 116:II_838, Abstract 3691.

63. Sacks FM, Carey VJ, Fruchart JC. Combination lipid therapy in type 2 diabetes. N Engl J Med. 2010; 12; 363(7):692. author reply 694-5. Meta-analysis of the major clinical trials of fibrate treatment found that fibrates reduced CHD events among patients with hypertriglyceridemia and low HDL-C.

64- Jun M, Foote C, Lv J, et al. Effects of fibrates on cardiovascular outcomes: a systematic review and meta-analysis. Lancet. 2010; 375(9729):1875-84. This reference is important because it reviews inconsistent findings from several clinical trials regarding the effect of fibrates on cardiovascular risk concluding that fibrates can reduce the risk of major coronary events, and might have a role in individuals at high risk of cardiovascular events and in those with combined dyslipidemia. [PubMed: 20462635]

65. Kamanna VS, Kashyap ML. Mechanism of action of niacin. Am J Cardiol. 2008; 101:20B-26B. [PubMed: 18157959]

66. Coronary Drug Project Research Group. Clofibrate and niacin in coronary heart disease. JAMA. 1975; 231:360-81. [PubMed: 1088963]

67. Canner PL, Berge KG, Wenger NK, et al. Fifteen year mortality in Coronary Drug Project patients: long-term benefit with niacin. J Am Coll Cardiol. 1986; 8:1245-55. [PubMed: 3782631]

68. AIM-HIGH Investigators. The role of niacin in raising high-density lipoprotein cholesterol to reduce cardiovascular events in patients with atherosclerotic cardiovascular disease and optimally treated low-density lipoprotein cholesterol Rationale and study design. The Atherothrombosis Intervention in Metabolic syndrome with low HDL/high triglycerides: Impact on Global Health outcomes (AIM-HIGH). Am Heart J. 2011; 161(3):471-477. [PubMed: 21392600]

69. Harris WS, Miller M, Tighe AP, et al. Omega-3 fatty acids and coronary heart disease risk: clinical and mechanistic perspectives. Atherosclerosis. 2008; 197:12-24. [PubMed: 18160071] 
70. Balk, E.; Chung, M.; Lichtenstein, A., et al. AHRQ publication No. 04-E010-2. Rockville, MD: Agency for Healthcare Research and Quality; 2004. Effects of Omega-3 Fatty Acids on CardiovascularRisk Factors and Intermediate Markers of Cardiovascular Disease. Evidence Report/Technology Assessment No. 93 (prepared byTufts-New England Medical Center Evidence-Based Practice Center under contract No. 290-02-0022).

71. Kris-Etherton PM, Harris WS, Appel LJ. American Heart Association Nutrition Committee. Fish consumption, fish oil, omega-3 fatty acids, and cardiovascular disease [published correction appears in Circulation 2003;107:512]. Circulation. 2002; 106:2747-2757. [PubMed: 12438303]

72. Marik PE, Varon J. Omega-3 dietary supplements and the risk of cardiovascular events: a systematic review. Clin Cardiol. 2009; 32(7):365-72. [PubMed: 19609891]

73. Yokoyama M, Origasa H, Matsuzaki M, et al. Japan EPA Lipid Intervention Study (JELIS) Investigators. Effects of eicosapentaenoic acid on major coronary events in hypercholesterolaemic patients (JELIS): a randomised open-label, blinded endpoint analysis. Lancet. 2007; 369:1090-8. [PubMed: 17398308]

74. Fox CS, Massaro JM, Hoffmann U, et al. Abdominal visceral and subcutaneous adipose tissue compartments: association with metabolic risk factors in the Framingham Heart Study. Circulation. 2007; 116:39-48. [PubMed: 17576866]

75. Sacks FM, Bray GA, Carey VJ, et al. Comparison of weight-loss diets with different compositions of fat, protein, and carbohydrates. N Engl J Med. 2009; 360:859-873. [PubMed: 19246357]

76. Appel LJ, Sacks FM, Carey VJ, et al. OmniHeart Collaborative Research Group. Effects of protein, monounsaturated fat, and carbohydrate intake on blood pressure and serum lipids: results of the OmniHeart randomized trial. JAMA. 2005; 294:2455-2464. [PubMed: 16287956]

77. Durstine JL, Grandjean PW, Cox CA, Thompson PD. Lipids, lipoproteins and exercise. J Cardiopulm Rehabil. 2002; 22:385-398. [PubMed: 12464825]

78. Fruchart JC, Sacks FM, Hermans MP, et al. Residual Risk Reduction Initiative (R3I). The Residual Risk Reduction Initiative: a call to action to reduce residual vascular risk in dyslipidaemic patient. Diab Vasc Dis Res. 2008; 5(4):319-35. [PubMed: 18958843]

79. Poobalan A, Aucott L, Smith WC, et al. Effects of weight loss in overweight/obese individuals and long-term lipid outcomes: a systematic review. Obes Rev. 2004; 5:43-50. [PubMed: 14969506]

80. Brown, B.; Canner, PL.; McGovern, ME., et al. Nicotinic acid. In: Ballantyne, C., editor. Clinical Lipidology, A Companion to Braunwald's Heart Disease. Philadelphia, PA: Saunders; 2009. p. 298-314.

81. Jones, PH. Fibrates. In: Ballantyne, C., editor. Clinical Lipidology, A Companion to Braunwald's Heart Disease. Philadelphia, PA: Saunders; 2009. p. 315-325.

82. Harris, WS.; Jacobson, TA. Omega-3 Fatty Acids. In: Ballantyne, C., editor. Clinical Lipidology, A Companion to Braunwald's Heart Disease. Philadelphia, PA: Saunders; 2009. p. 326-338.

83. Fontana L, Villareal DT, Weiss EP, et al. the Washington University School of Medicine CALERIE Group. Calorie restriction or exercise: effects on coronary heart disease risk factors: a randomized, controlled trial. Am J Physiol Endocrinol Metab. 2007; 293:E197-E202. [PubMed: 17389710]

84. Ridker PM, Danielson E, Fonseca FA, et al. JUPITER Study Group. Rosuvastatin to prevent vascular events in men and women with elevated C-reactive protein. N Engl J Med. 2008; 359:2195-2207. [PubMed: 18997196] 
Table 1

Serum TG categories and treatment goals from the third report of the NCEP ATP III

\begin{tabular}{|l|l|l|l|}
\hline Category & $\begin{array}{l}\text { Serum TG } \\
\text { level }(\mathbf{m g} / \mathbf{d L})\end{array}$ & ATP III treatment goals & Treatment modality to address high TG level \\
\hline Normal & $<150$ & Primary prevention & \\
\hline Borderline & $150-199$ & Primary goal: achieve LDL-C goal & Lifestyle changes \\
\hline High & $200-499$ & $\begin{array}{l}\text { Primary goal: achieve LDL-C goal } \\
\text { Secondary goal: achieve non-HDL-C goal (30 } \\
\text { mg/dL above LDL-C goal) }\end{array}$ & $\begin{array}{l}\text { Lifestyle changes } \\
\text { Statins as first line } \\
\text { Consider niacin or fibrate if low HDL-C or as adjunct } \\
\text { therapy }\end{array}$ \\
\hline Very high & $>500$ & $\begin{array}{l}\text { Primary goal: TG level reduction to avoid } \\
\text { pancreatitis } \\
\text { Secondary goal: CVD prevention }\end{array}$ & $\begin{array}{l}\text { Lifestyle changes: Low-fat diet (< 15\% total calories } \\
\text { from fat), low-carbohydrate diet } \\
\text { Fibrates, niacin, or High-dose omega-3 fatty acids (up to } \\
\text { 3-4 g/d) }\end{array}$ \\
\hline
\end{tabular}

CVD-cardiovascular disease; HDL-C-high-density lipoprotein cholesterol; LDL-C-low-density lipoprotein cholesterol; NCEP ATP III-National Cholesterol Education Program Adult Treatment Panel III; TG-triglyceride.

(Data from NCEP ATP III] [2].) 
Table 2

Effects of lifestyle practices and lipid-lowering therapies on TG level reduction

\begin{tabular}{|c|c|}
\hline Therapeutic intervention & $\%$ TG reduction \\
\hline \multicolumn{2}{|l|}{ Lifestyle changes } \\
\hline Weight loss (5\% to $10 \%$ total body weight) & 20 \\
\hline Diet & $10-15$ \\
\hline \multicolumn{2}{|l|}{ Aerobic exercise (dependent on baseline TG levels) } \\
\hline TG level $>150 \mathrm{mg} / \mathrm{dL}$ & $15-20$ \\
\hline Coupled with weight loss & $20-30$ \\
\hline \multicolumn{2}{|l|}{ Pharmacologic therapy } \\
\hline Fibrates (increased reductions are observed at higher pretreatment TG levels) & $30-50$ \\
\hline Niacin (dose dependent ranging from $1-2 \mathrm{~g} / \mathrm{d}$ ) & $10-30$ \\
\hline \multicolumn{2}{|l|}{ Omega-3 PUFAs (dose dependent) } \\
\hline Per every 1-g PUFA & $5-10$ \\
\hline High-dose PUFA (3-4 g/d) & $25-30$ \\
\hline \multicolumn{2}{|l|}{ Statins } \\
\hline Low-intensity statins (eg, pravastatin $40 \mathrm{mg} / \mathrm{d}$, simvastatin $20-40 \mathrm{mg} / \mathrm{d}$, atorvastatin $10 \mathrm{mg} / \mathrm{d}$ ) & $10-15$ \\
\hline High-intensity statins (eg, atorvastatin $80 \mathrm{mg} / \mathrm{d}$, rosuvastatin $20-40 \mathrm{mg} / \mathrm{d}$ ) & $15-30$ \\
\hline Ezetimibe & $5-10$ \\
\hline
\end{tabular}

PUFA-polyunsaturated fatty acid; TG-triglyceride. (Data from $[71,77,79-84]$.) 